\title{
A Band-Rejection Vivaldi Antenna with High Selectivity Using Hybrid HRW/CCLL
}

\author{
Mengfei Xiong (D), Junping Duan (D), and Binzhen Zhang $(\mathbb{D}$ \\ Key Laboratory of Instrumentation Science and Dynamic Measurement, Ministry of Education, North University of China, \\ Taiyuan 030051, China \\ Correspondence should be addressed to Binzhen Zhang; zhangbinzhen@nuc.edu.cn
}

Received 28 October 2019; Revised 24 January 2020; Accepted 24 February 2020; Published 23 April 2020

Academic Editor: Giorgio Montisci

Copyright $(92020$ Mengfei Xiong et al. This is an open access article distributed under the Creative Commons Attribution License, which permits unrestricted use, distribution, and reproduction in any medium, provided the original work is properly cited.

A simplified notched design method for the Vivaldi antenna is exhibiting high frequency-band-selectivity characteristics. By suitably introducing half-wavelength resonator (HWR) and complementary capacitively loaded loop (CCLL), the notched-band selectivity is promoted while maintaining the wide impedance bandwidth of the antenna applicable for wireless communications. HWR is bent in the middle to focus the first notch pole, and the second notch pole is obtained by CCLL on the radiating patch. Additionally, the resonant frequency of the notched pole can be determined by the position and size of two loaded resonators in theoretical analysis, thereby realizing a wideband antenna with the desired notched band. Finally, the Vivaldi antenna of loading resonator was fabricated to verify the feasibility of this new method. Measured and simulated experimental results reveal that the antenna exhibits directional pattern in the passband, low gain at the band-rejection, and excellent selectivity within a frequency range. The simulation and measurement results are in good agreement. The proposed antenna achieves $\mathrm{S} 11<-10 \mathrm{~dB}$ in 2.6-13.7 GHz and a notch band from 4.49 to $6.64 \mathrm{GHz}$ to reject IEEE 802.11a and HIPERLAN/2 frequency band. Moreover, the proposed antenna has good frequency selectivity, and its gain is good enough in the passband with peak gain up to $10.8 \mathrm{dBi}$. This antenna design presents frequency suitability, demonstrating that a UWB antenna with a controllable notched band has been realized.

\section{Introduction}

Recently, the limited electromagnetic spectrum resources are more and more challenging to meet the increasing demand for frequency. Because of the excellent performance of approved $3.1-10.6 \mathrm{GHz}$ band ultrawide bandwidth (UWB) antenna in data transmission and power consumption, UWB communication has been the focus of research for a long time [1]. UWB wireless communication has attracted worldwide attention because of its robustness of high data rate transmission and fading, as well as other advantages of low cost and low loss penetration $[2,3]$. It can be predicted that the UWB wireless communication system has the potential to realize universal communication requirements to meet the user allocation requirements of today's dense network equipment [4]. Although the frequency band is far from being fully utilized, the pressure can be relieved by eliminating the frequency interference between the UWB communication system and WLAN band $(5.15-5.825 \mathrm{GHz})[5,6]$. Therefore, it is of considerable significance to develop broadband antennas with notch bandwidth. There are two main methods for realizing a notch band. The first method is to etch grooves and slits on the ground or the radiation patch [7-11], and the other is to add different structure resonators on or near the excitation source [12-15]. However, the notch produced by etching the slit or introducing the resonator shows only one pole in the slit, which is not enough to improve the selectivity. In [4], the selectivity of the notch band is improved by introducing two poles at the same time, but the radiation gain of two poles is limited.

UWB technology has been accepted by most countries in the world. Different UWB antennas including dielectric resonator antenna, printed slot antenna, printed monopole 
antenna, and planar microstrip patch antenna have been proposed successively [16]. Among them, the Vivaldi antenna is one type of directional antenna that can introduce notched band while maintaining an excellent radiation characteristic. Currently, there are several ways for implementing a notched Vivaldi antenna, including etching slot in the radiating element $[17,18]$, introducing several resonators to generate several band-notched characteristics $[19,20]$, and loading a rectangular resonator near the excitation source $[21,22]$. However, these designs usually cause a relatively flat transition band and low radiation gain between the notch and the working band, which limits their application.

In this article, a new method is presented to design a notch-band Vivaldi antenna with improved frequency selectivity. In order to achieve this goal, a half-wavelength resonator (HWR) and a slotted-complementary capacitively loaded loop (CCLL) are introduced into the traditional Vivaldi antenna, and a notch bandwidth response in WLAN band is obtained. By analyzing the resonant characteristics of two loaded resonators, their frequency positions can be determined, and the hybrid resonator/loop can be formed. The combined bottom layer and top layer can make full use of the circuit board, without increasing the circuit size.

\section{Design of the Proposed Antenna}

Using a composite structure formed by open-circuited resonator and slits, a specific notch band with sufficient suppression bandwidth can be obtained, which brings a filtering frequency with high selectivity function in limited band. A microstrip line with a notched band feeds the original Vivaldi antenna (Antenna-O), and the proposed Vivaldi antenna (Antenna-N) is shown in Figures 1(a) and 1(b), respectively. The Antenna-O dimension $\left(73 \times 45 \times 0.787 \mathrm{~mm}^{3}\right)$ is printed on a Rogers 5880 substrate (permittivity of $\varepsilon_{r}=2.2$ ). The excitation of the antenna is given by using a microstrip line with impedance transition techniques to match $50 \Omega$ SMA connectors. The exponential tapered curve adopted in this design can be expressed by

$$
\begin{aligned}
y & =C_{1} e^{R z}+C_{2}, \\
C_{1} & =\frac{y_{2}-y_{1}}{e^{R z_{2}}-e^{R z_{1}}}, \\
C_{2} & =\frac{y_{1} e^{R z_{2}}-y_{2} e^{R z_{1}}}{e^{R z_{2}}-e^{R z_{1}}},
\end{aligned}
$$

where $R$ is the exponential factor which controls the beam width of the slot. In our design, $R$ is set as 0.09 , and the width $\left(W_{1}\right)$ and length $\left(L_{1}\right)$ of slot line are $26 \mathrm{~mm}$ and $57.785 \mathrm{~mm}$. On the back of the substrate, a microstrip line crosses perpendicular to the slot line. The impedance-matching circuit is included in the feeding line, whose impedance depends upon its width as current is mainly distributed at its upper edge. The microstrip to slot-line transition is realized by etching the slot line on one side of a substrate. Moreover, the optimized dimensions of the Antenna-O are summarized as follows: $R_{2}=7, R_{1}=6.5, L_{4}=7.04, W_{4}=0.8$,
$L_{3}=6.68, W_{3}=1.43, L_{2}=15.93$, and $W_{2}=1.83$. The Antenna$\mathrm{T}$ is a tapered slot antenna which ensures a good impedance match with $|S 11|<10 \mathrm{~dB}$ over a frequency range of $2.2-13.9 \mathrm{GHz}$.

2.1. Open-Circuited Resonator. With the correct introduction of HWR and CCLL, the Vivaldi antenna can realize an antenna with two notch poles inside the operation band, as shown in Figure 1(b). For the first notch pole, it is caused by the HWR mounted above the circular groove. When the signal is emitted from the microstrip feed, it will couple to the underlying gradient slot. The signal will then pass through the circular slot and be coupled to the HWR. When the boundary condition of symmetry plane agrees with the boundary condition of the groove, the coupling will occur at the top of HWR to achieve the strongest energy. The structure of HWR is symmetrical about the $z$-axis with a centre point that is the same as the centre of the circular bottom groove. The input impedance of the resonator can be expressed as $Z_{i}=j Z_{0} \cot \theta$. When the resonance is applied, with $\theta=2 \pi f L \sqrt{\varepsilon} / c$ and $Z_{i}=0$, the relation between the notched operating frequency and the length can be derived as

$$
\begin{array}{r}
f_{\text {notch }}=\frac{c}{4 L \sqrt{\varepsilon_{e f f}}}, \\
\varepsilon_{\text {eff }}=\frac{\left(\varepsilon_{r}+1\right)}{2},
\end{array}
$$

where $L$ is a function of $\alpha$ and $L_{5}$, corresponding to the actual length of $\theta$. The electrical length of the HWR is approximately half wavelength at the frequency centre rejected $f_{\text {notch }} \cdot \varepsilon_{r}$ is the relative dielectric constant, $\varepsilon_{\text {eff }}$ is the effective dielectric constant, and $c$ is the speed of light. The notched band antenna is simulated and optimized according to the above designing principles. With the insertion of the slot, we got notched band at $3.6-4.6 \mathrm{GHz}$. For demonstration, Figures 2(a) and 2(c) show the VSWR and the approximate equivalent circuit of the antenna.

As shown in Figure 2(b), the locations of the first notched pole varying are displayed with different angles of the HWR. As $\alpha$ increases from $69.5^{\circ}$ to $48.5^{\circ}$, the central frequency of the notch band goes up from 4.3 to $5.01 \mathrm{GHz}$, and its absolute bandwidth decreases from 1.02 to $2.3 \mathrm{GHz}$. The reduction in resonator angle shifts the operating frequency to the desired frequency band and has a wider bandwidth with a higher notch value. The change of angle $\alpha$ can take proper effect on the convergence of electromagnetic waves, while the matching wavelength can be adjusted by the length change of HWR. It is worth noting that the angle of resonator did not only improve the notched band effectively but also contribute to the impedance improvement of the antenna.

2.2. Complementary Capacitively Loaded Loop. The performance of the single-pole has room for further improvement. The second notch position is obtained by the slot line resonator. In the first step, a curved groove line is used at the 

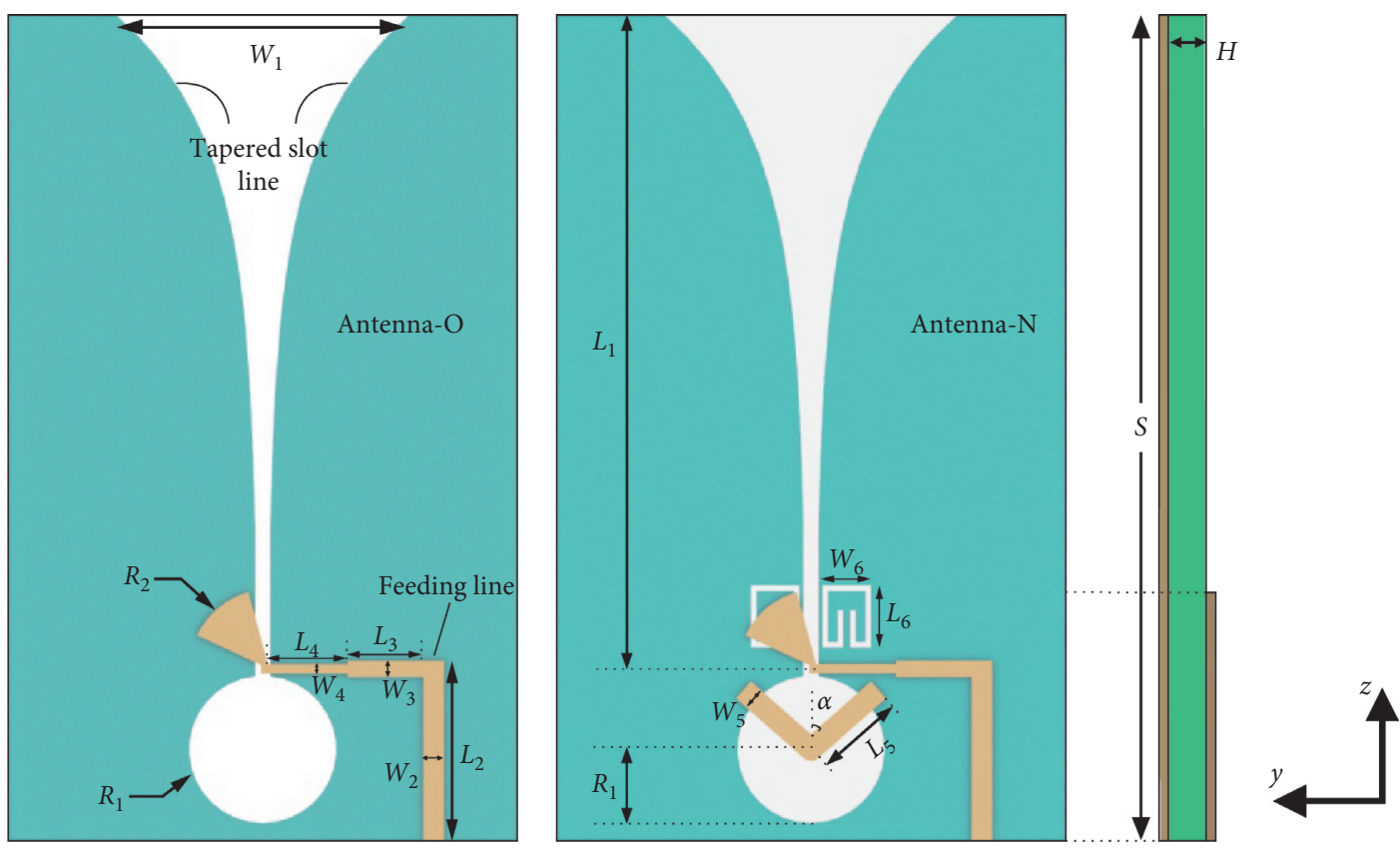

Top layer

Bottom layer

Substrate

(a)

(b)

(c)

FIgURE 1: Geometry and configuration of the UWB antennas. (a) Original Vivaldi antenna. (b) Proposed Vivaldi antenna with a notched band. (c) Side view.
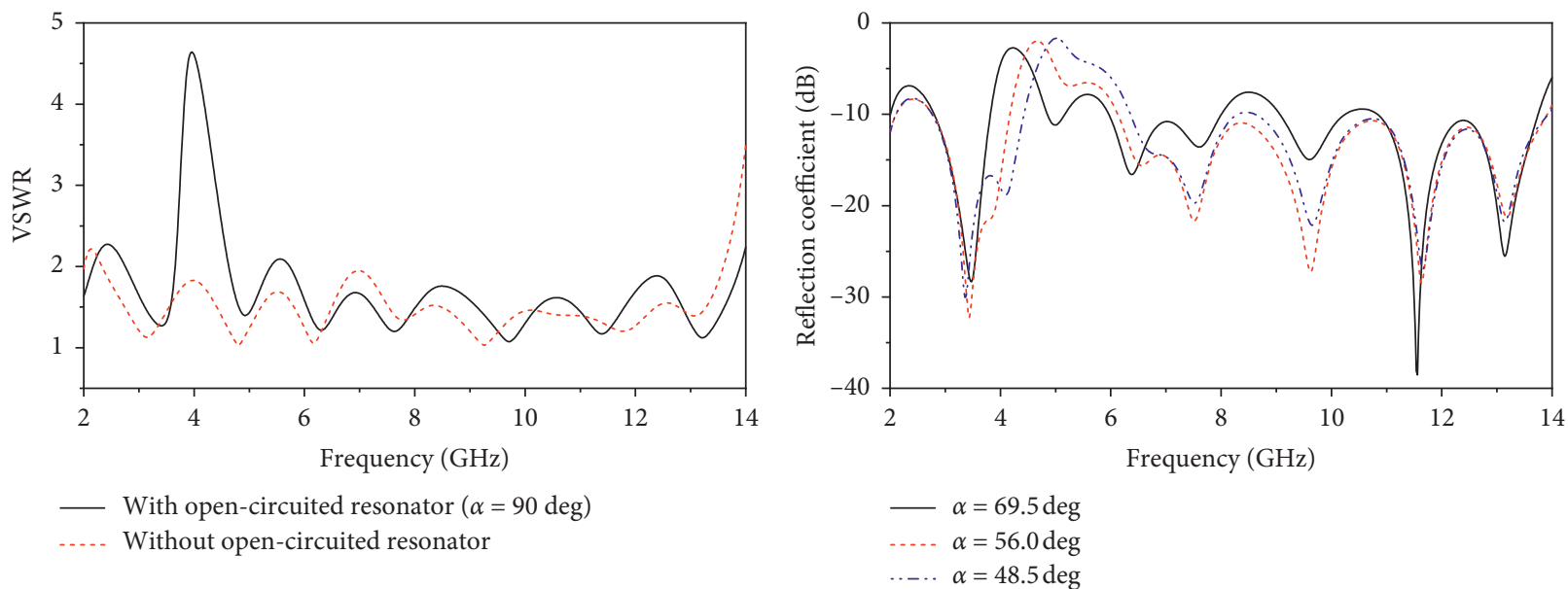

(a)

(b)

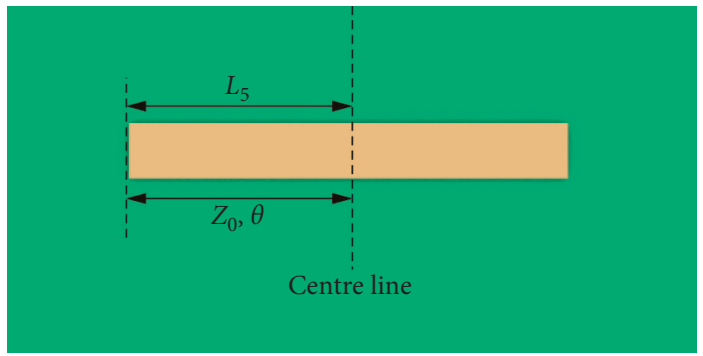

(c)

FIGURE 2: (a) VSWR of the antenna with the conventional Vivaldi antenna and modified patch. (b) Return loss varies according to the angle $\alpha$. (c) The approximate equivalent circuit of the first pole. 
top side of the dielectric substrate. As shown in Figure 3(a), this results in reflection with maxima at $5.86 \mathrm{GHz}$. Following this, the dimension-optimized slot line is extended to form a split ring on the original structure which improves the peak value, albeit a slight decrease in the bandwidth level. Hence, in order to increase the roll-off performance while maintaining the low reflection levels, the split-ring slot is extended in the design, which along with $z$-axis is placed near the gap of asymptote. The complementary split ring in Figure 3(b) displays one peak at $5.78 \mathrm{GHz}$ while maintaining reflection magnitude $-2.4 \mathrm{~dB}$ for the resultant band. Due to the ring shape resonances, the low region of the reflection spectrum shows a magnitude of approximately $-8.1 \mathrm{~dB}$. The notch position of the new reflection spectrum shows the same trend in both extension directions. The length of the total length is constant. Compared with a single slot line, the degree of impedance matching after bending is improved, and the influence on the high-frequency portion is small. To ensure consistent strength of notch band, maintain a stable distance from the gradient line and the feed line of the bottom. The gaps are placed in horizontal directions to maintain the geometric symmetry. As a magnetic resonance structure that is responding to vertical magnetic fields, CCLL can be used to create band notches for UWB antennas. The roll-off performance of the antenna with notch band can be improved by introducing a CCLL on both sides of the asymptote groove line to introduce another notched pole.

In fact, when the split-ring resonance is in a time-varying electromagnetic field, the metal ring generates an induced current, and due to the presence of the opening, the internal and external metal rings on the same side gradually accumulate a different electric charge to form a displacement current. According to the dual principle, if the metal surface is an ideal electrical conductor (PEC), the gap is the ideal magnetic conductor [23]. Therefore, CCLL can generate strong resonance when the CCLL structure is subjected to a time-varying electric field or a time-varying magnetic field along the opening direction of the ring and parallel to the torus. Since the operation of the typical Vivaldi antenna depends on the microstrip feed, the bandgap characteristics are affected by the position of CCLL on the antenna. E-field distribution and the specific configuration of CCLL are shown in Figures 4 and 5, respectively. The improvement is to change the closing loop on the inner ring and enhance the coupling between the outer and the inner loops, which enables an effective notch band. The inner ring length $L_{d}$ of CCLL can also be used to adjust the frequency position of the second notch pole.

Therefore, to realize the notch band and roll-down characteristics of the designed notch poles, two appropriate structural parameters of the load resonators can be selected using the relationship shown in Figures 2 and 3. The positions of the HWR and CCLL elements relative to the feeder and slot lines can be further fine-tuned to obtain the best impedance matching.

2.3. High Selectivity Analysis. Desired strong coupling is realized by changing the position between microstrip and slot line portions. A hybrid notched structure is adopted to develop a novel UWB antenna with a controllable notch band. Notched band function is one of the critical characteristics of the UWB antennas, especially at on-demand WLAN band to avoid the interferences with the existing licensed bands. By analyzing the current distribution on the Antenna-N at different notch frequencies, the implementation mechanism of the notch band can be further understood. The current is mainly concentrated in the HWR at $5 \mathrm{GHz}$, as shown in Figure 6(a). On the contrary, based on Figure 6(b), the current distributes primarily between the inner rings of the CCLL at $5.9 \mathrm{GHz}$. As a result, by distributing two notch poles in the vicinity, the antenna can hardly radiate at the two frequencies, achieving the expected notch pole.

In the applications of IEEE 802.11a, HIPERLAN/2 and other narrow-band systems, the selectivity of notched antennas is an essential factor affecting the design of notched antennas, defining the ratio of $-3 \mathrm{~dB}$ bandwidth to $-10 \mathrm{~dB}$ bandwidth as the roll-off criterion to facilitate the evaluation of the notch band selectivity. Figure 7 shows a simulation S11 of three types of antennas for comparison. The notch band of antenna with HWR and CCLL has a higher roll-off property comparing with the other antennas. For the final antenna, the roll-off ratio reaches 0.67 , while, for antennas with HWR and CCLL, it is only 0.41 and 0.46 , respectively. Also, the return loss of the notch band of the Antenna-N reaches $-1.24 \mathrm{~dB}$, which means that most of the signals in the notch band are reflected. It can be seen that the selective performance of the notch band can be greatly improved by the positional parameter of the resonator.

\section{Results and Discussion}

3.1. Group Delay for Face-to-Face. The degree of distortion in the UWB antenna can be characterized using group delay. A stable group delay with less nonuniformity is always desirable for the whole UWB frequency range in a UWB system. The group delay of the proposed antenna is measured by placing two designed antennas at a distance of $10 \mathrm{~cm}$ and is shown in Figure 8. The group delay is less than $1 \mathrm{~ns}$ throughout the operating band except in the notched bands ( $>9 \mathrm{~ns}$ ). Other than the notched bands, the group delay is relatively flat, which indicates that the proposed antenna exhibits linear transmission performance.

3.2. Antenna Performance and Analysis. To study the rationality of the notched Vivaldi antenna proposed operating in the $5-6 \mathrm{GHz}$ band, the antenna prototype was fabricated on $31 \mathrm{mil}(0.78 \mathrm{~mm})$ thick available substrate of Rogers 5880 for experimental verification is shown in Figure 9(a). Agilent vector network analyzer has been used to measure S11 and radiation characteristics of the designed antenna. The result of manufacturing and measurement are shown in Figure 9(b); the simulation results are consistent with the data of measurement. It is clear from the results that the antenna operates at a bandwidth from 2.6 to $13.7 \mathrm{GHz}$ with the band-rejection function in the WLAN band. The 


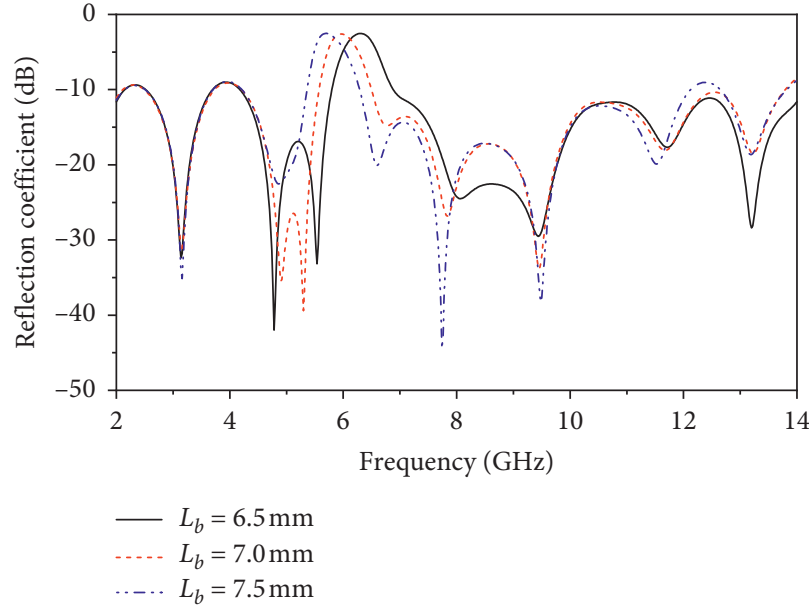

(a)

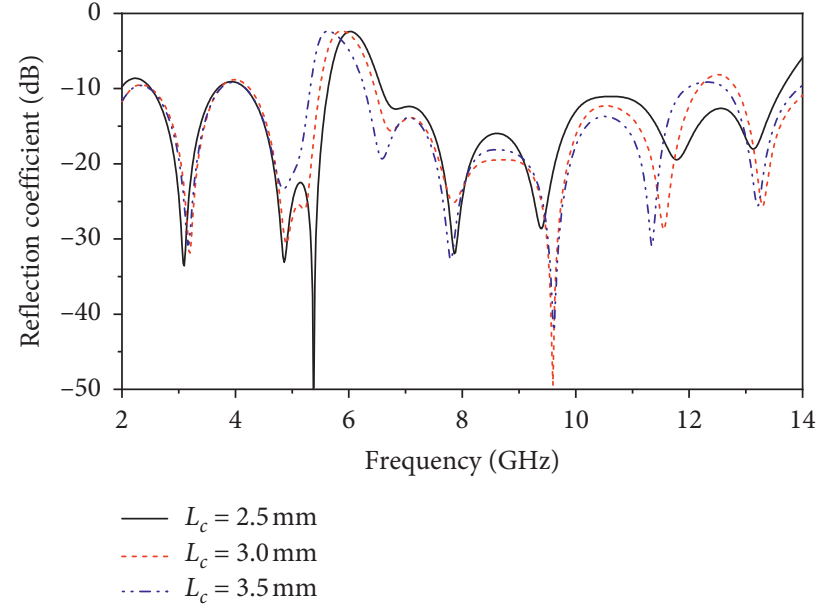

(b)

Figure 3: Notch frequency for different geometrical etched slot parameters. (a) The ordinary rectangular slot at the different frequency band from varying the parameter $L_{b}$. (b) The complementary split-ring resonance at the different frequency band from varying the parameter $L_{c}$.

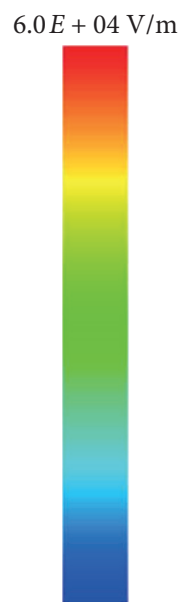

$2.0 E+02 \mathrm{~V} / \mathrm{m}$

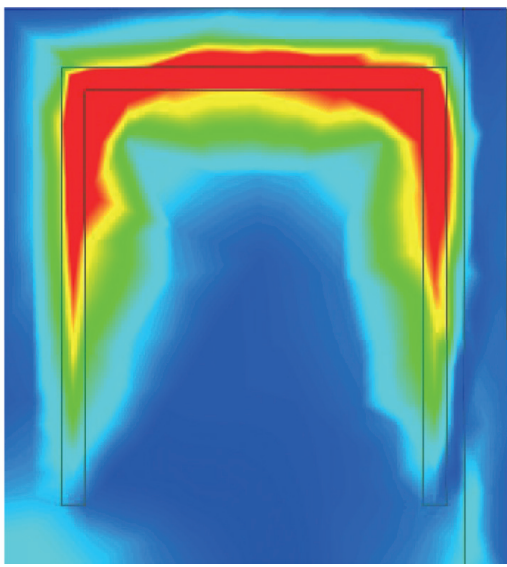

(a)

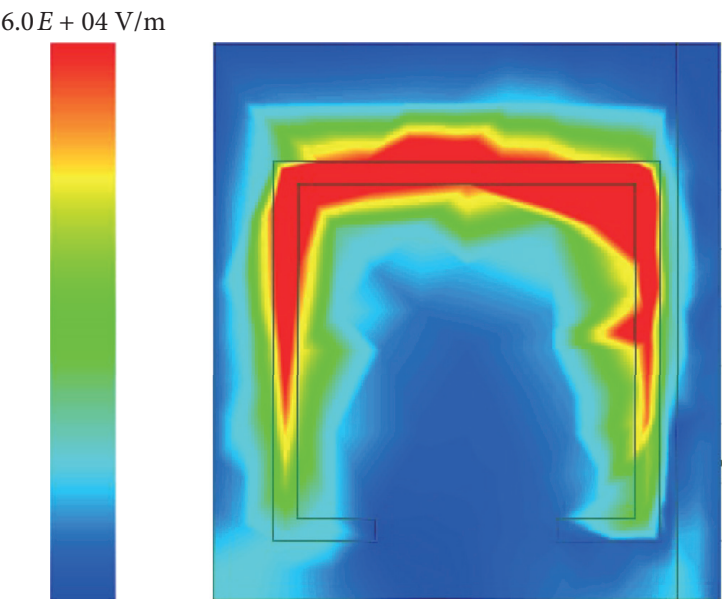

$2.0 E+02 \mathrm{~V} / \mathrm{m}$

(b)

$6.0 E+04 \mathrm{~V} / \mathrm{m}$

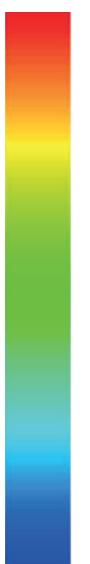

$2.0 E+02 \mathrm{~V} / \mathrm{m}$

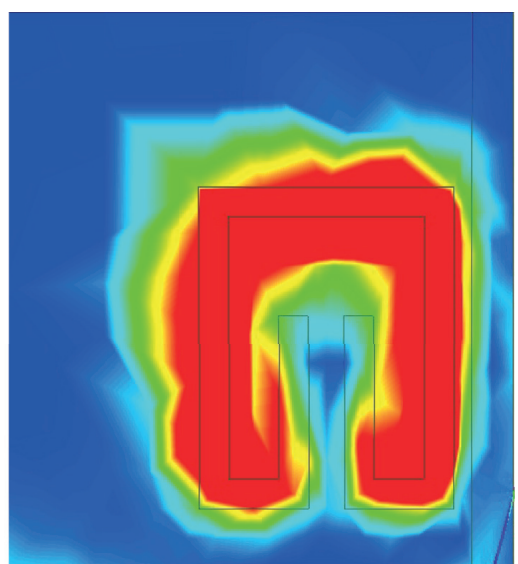

(c)

FIgURE 4: E-field distribution of slot line at different structure. (a) The ordinary rectangular slot. (b) The complementary split-ring slot with C-shape. (c) The CCLL. 


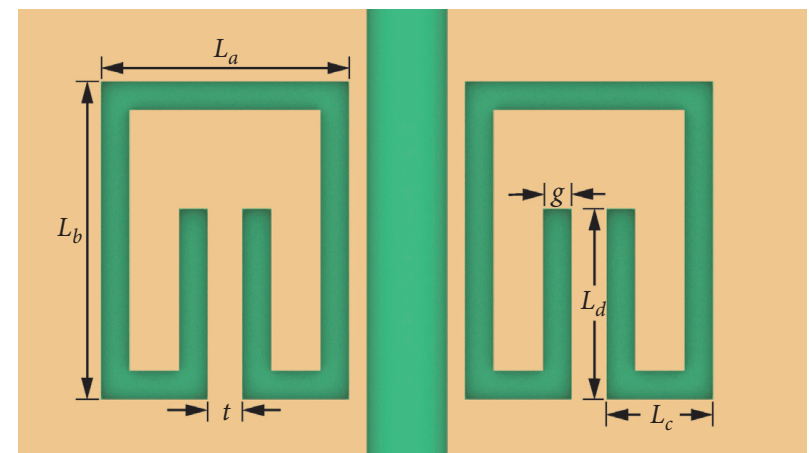

Figure 5: The coupling structure between the slot antenna and CCLL.

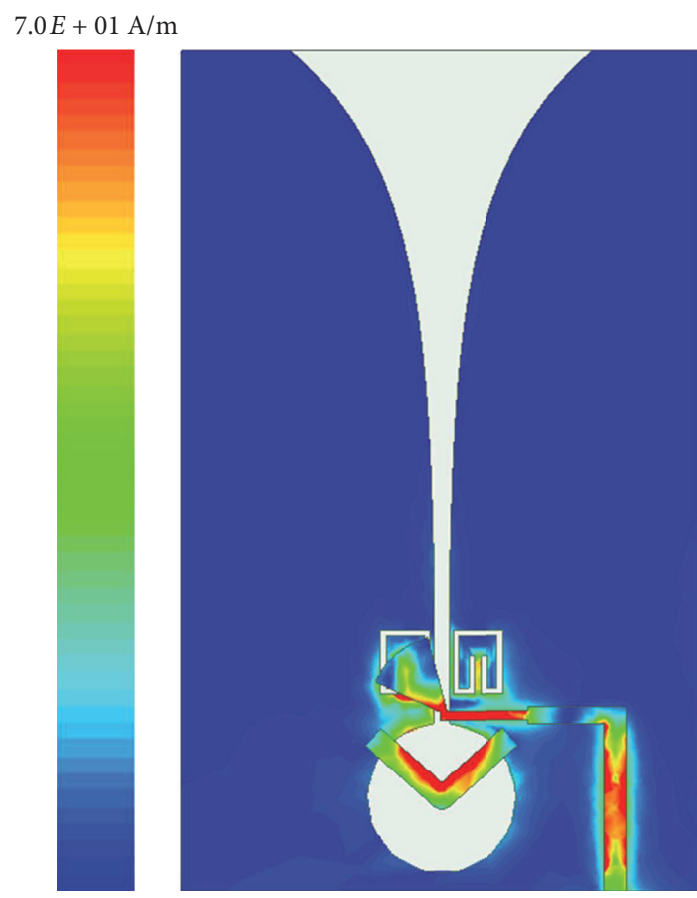

$0.0 E+00 \mathrm{~A} / \mathrm{m}$
$7.0 E+01 \mathrm{~A} / \mathrm{m}$

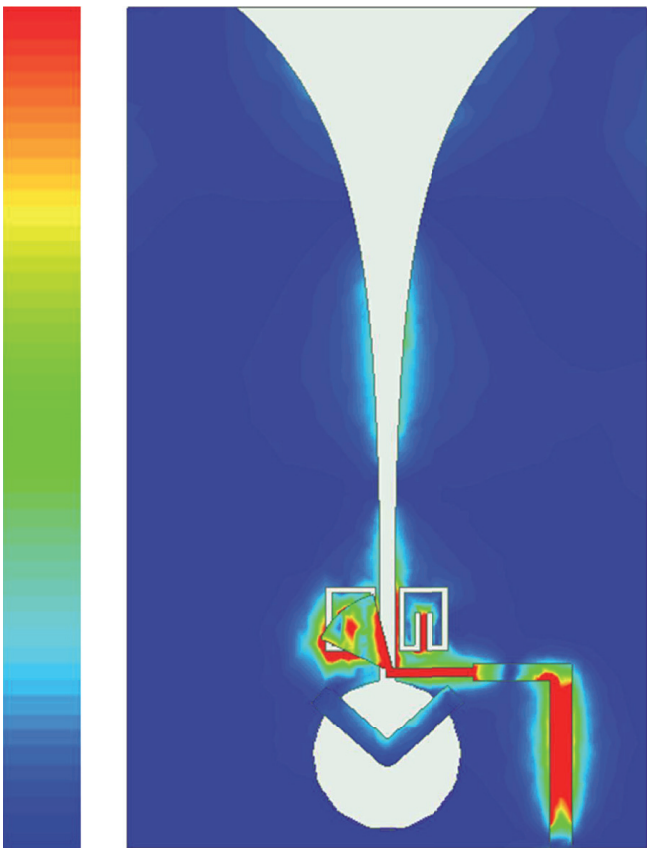

$0.0 E+00 \mathrm{~A} / \mathrm{m}$

(a)

(b)

FIGURE 6: Simulated surface current distribution on the radiating patch of the proposed antenna at the corresponding central frequency of the notched band at (a) $5 \mathrm{GHz}$ and (b) $5.9 \mathrm{GHz}$.

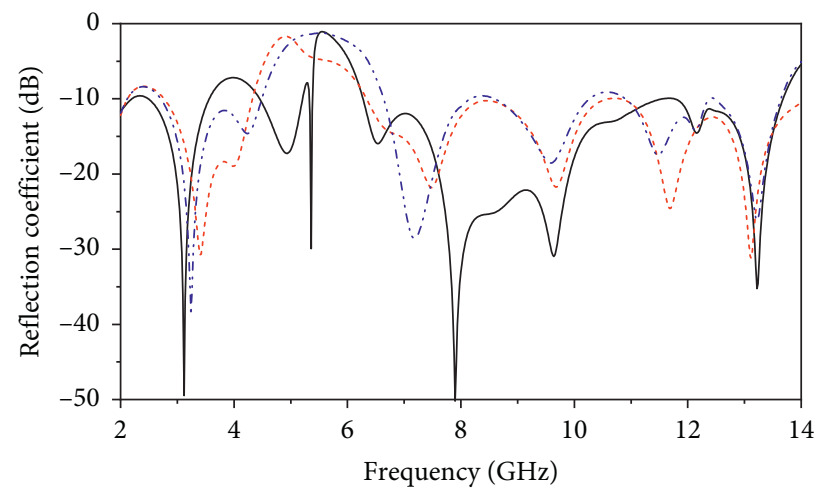

— With only CCL

With only HWR

..... With only CCL and HWR

FIgURE 7: Simulated characteristic of the Vivaldi antenna for different structure. 


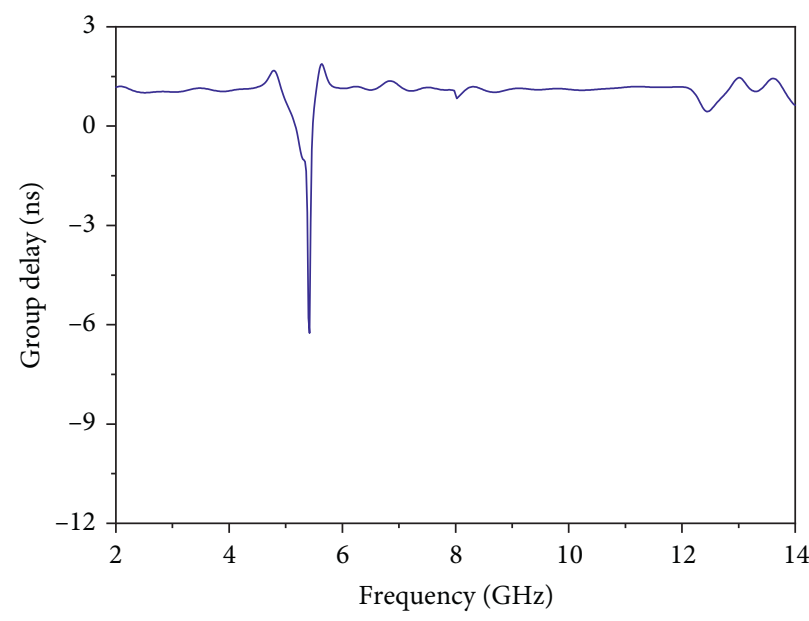

FIGURE 8: Group delay of the band-notched UWB antenna.
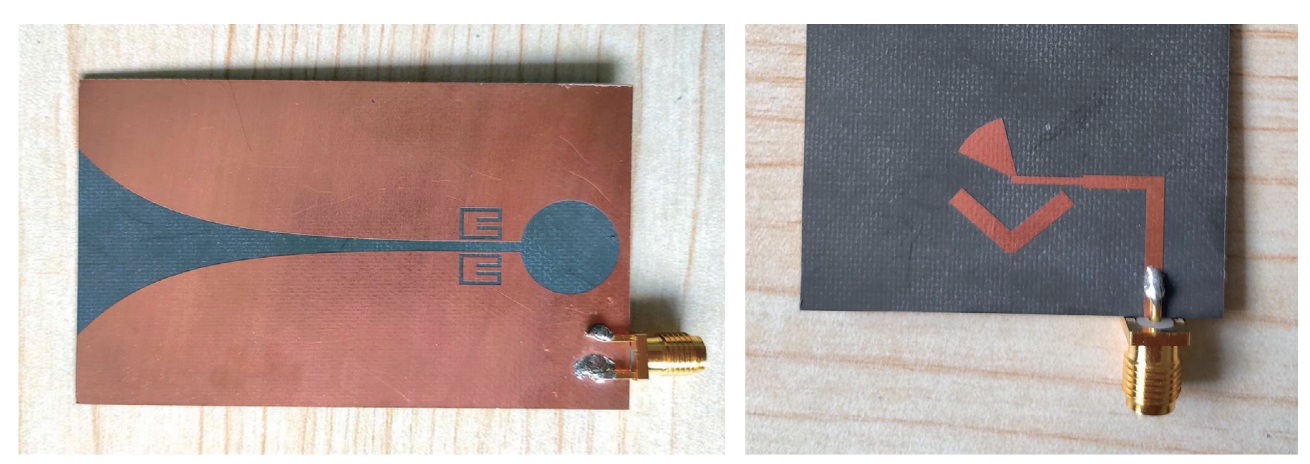

(a)

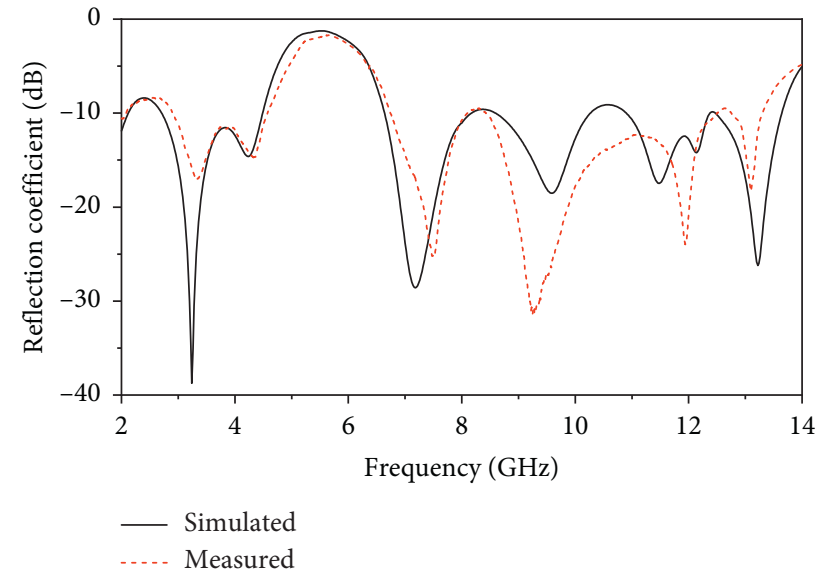

(b)

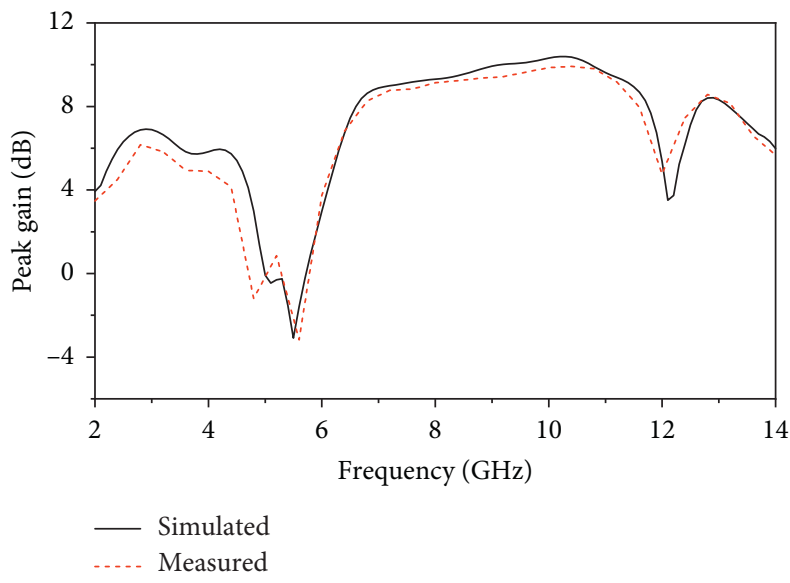

(c)

FIGURE 9: (a) Fabricated prototype of the Vivaldi antenna loaded with HWR/CCLL. (b) Simulated and measured S11 characteristics of the fabricated prototype with HWR/CCLL loading. (c) Measured and simulated gain characteristics of the fabricated prototype with HWR/ CCLL loading.

proposed antenna has a notch band of $4.49-6.64 \mathrm{GHz}$ at $5.5 \mathrm{GHz}$. The difference between the simulated and measured S11 results may be due to inaccurate processing and substrate loss tangent.

The simulated and measured gain of the final antenna is shown in Figure 9(c). It can be inferred that the gain of the proposed antenna is more than $2 \mathrm{dBi}$ in the whole frequency band. Notably, the gain drops sharply around the $5.5 \mathrm{GHz}$ frequency, which is in the band with notched poles. The results show that the good combination of the desired trap characteristics with the selected characteristics is suitable for WLAN band wireless communication applications.

Figure 10 shows the simulated and measured radiation patterns in E-plane ( $y z$-plane) and H-plane ( $x z$-plane) at 3, 7, 

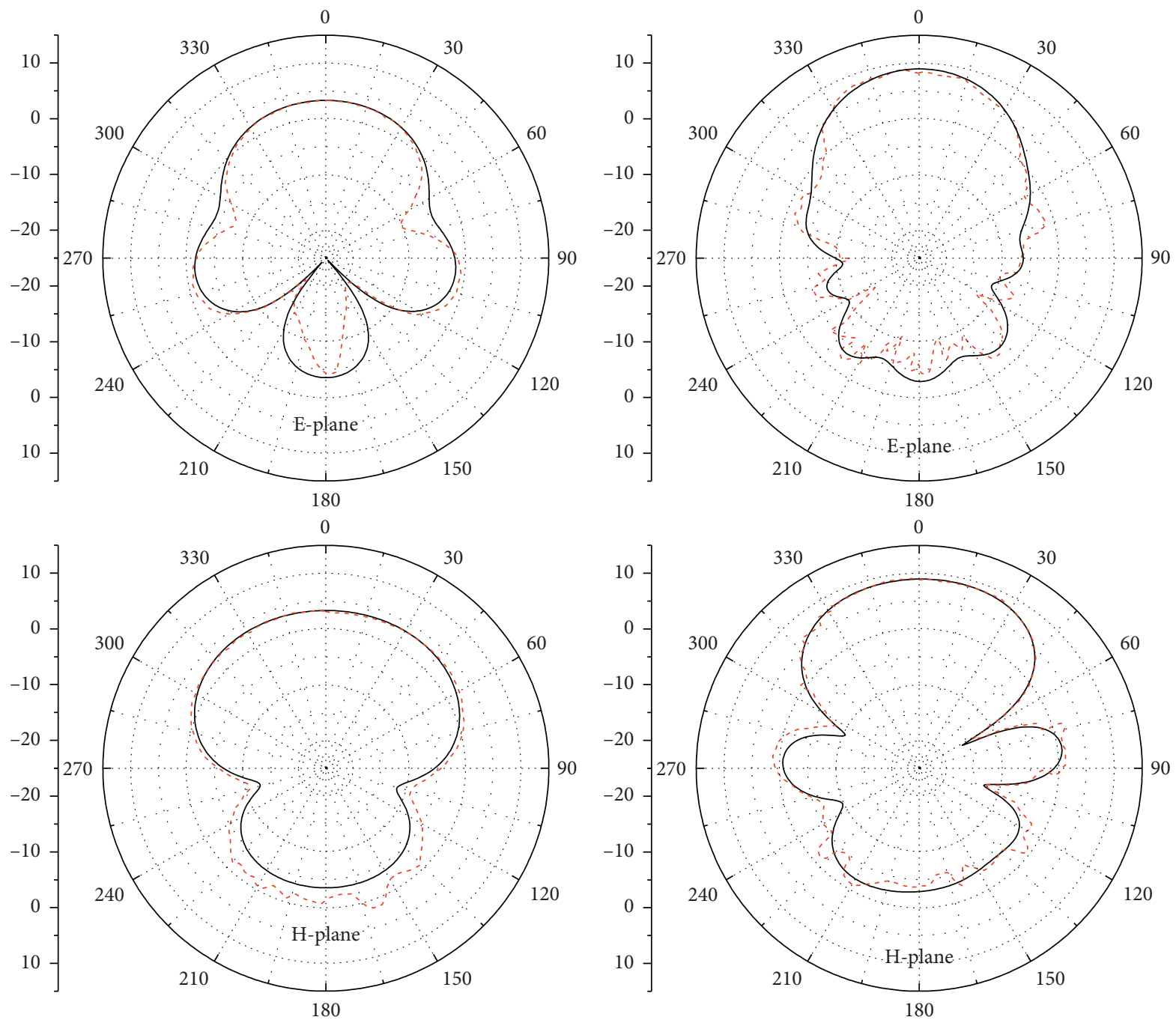

(a)

(b)

FIgURe 10: Continued. 

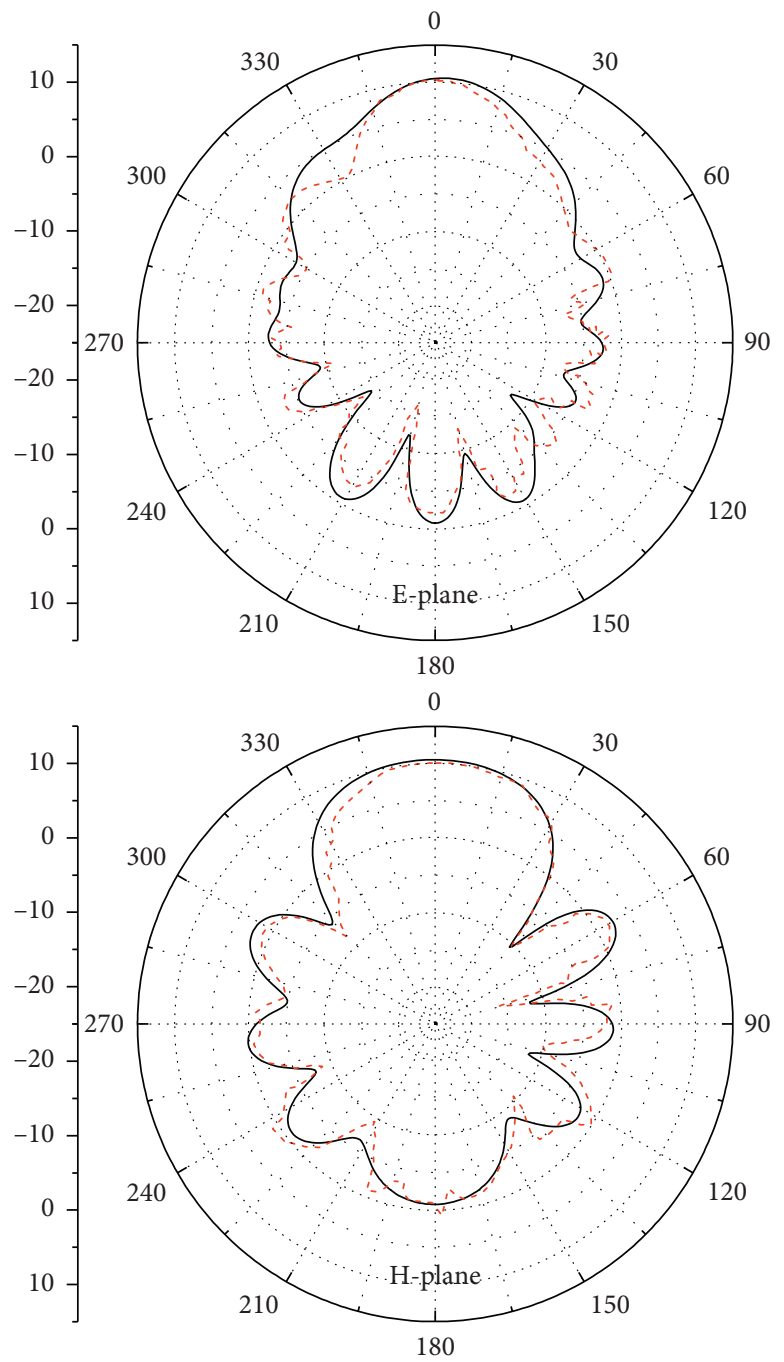

(c)

FiguRE 10: Simulated and measured radiation patterns for E-plane ( $y z$-plane) and H-plane ( $x z$-plane) of the fabricated antenna. (a) 3 GHz. (b) 7 GHz. (c) $10 \mathrm{GHz} .($ Sim. — , Mea. -- .)

and $10 \mathrm{GHz}$. The primary purpose of demonstrating the radiation patterns is to prove that the antenna works over a broad frequency band. The radiation pattern at E-plane is little deteriorated since the equivalent radiating area increased at high frequencies. The experienced results are in good agreement with the simulated results. Moreover, according to the plots, the proposed antenna exhibits good directional radiation patterns in the E- and $\mathrm{H}$-planes. Stable radiation directivity is achieved.

3.3. Comparison of Proposed Antenna with Other References. A comparison is made in Table 1, with other reported antennas in terms of size, bandwidth, and notching characteristics. Almost all the antennas have limited selectivity or low antenna gain. Although these antennas offer comparable notched structures size to our proposed geometry with Vivaldi antenna, most of the antennas reported in the literature have the drawbacks of complex antenna geometry with unstable radiation patterns as well as parasitic stubs and resonators being irregularly placed on the radiating and ground surfaces in model design. Furthermore, it should be noticed that, compared with the listed counterparts, the gain of the proposed Vivaldi antenna is significantly higher due to the directional characteristics of the end-fire antenna. In summary, the proposed antenna is superior to others in terms of notched-band selectivity and suppression level of the notched band due to its simple antenna configuration, notched tunability, radiation pattern stability, and symmetric etched slots. Therefore, it can be concluded that, by employing a hybrid resonator/loop, the selectivity performance of the notched band can be significantly improved while maintaining a higher radiation gain.

\section{Conclusions}

A band-rejection UWB antenna with high selectivity is proposed and studied for WLAN communication systems. 
TABLE 1: Comparison of the proposed antenna with other reported references.

\begin{tabular}{|c|c|c|c|c|c|c|}
\hline Antennas & $\begin{array}{l}\text { Coupling } \\
\text { structure }\end{array}$ & Dimension $(\mathrm{mm})$ & Bandwidth (GHz) & Rejection band (GHz) & Max gain (dBi) & $\begin{array}{l}\text { Selectivity/roll- } \\
\text { off }\end{array}$ \\
\hline$[24]$ & SIR & $27.5 \times 18$ & $2.78-12.3$ & $5-5.9$ & - & 0.33 \\
\hline [25] & C-shaped strip & $20 \times 20$ & $3.04-10.87$ & $5.03-5.94$ & $<4.5$ & - \\
\hline [26] & SRR/CPW & $47 \times 37$ & $2.8-13.5$ & $5.1-6.1$ & $<4$ & $<0.6$ \\
\hline [27] & CSRR & $68 \times 35$ & $3.1-10.65$ & $3.35-3.555 .65-5.95$ & 4.2 & - \\
\hline [28] & SRR/CSRR,/DGS & $30 \times 28$ & $3-10$ & $3.3-3.65 .15-5.827 .0-8.5$ & 5 & $<0.5$ \\
\hline [29] & RPR & $30 \times 22$ & $2.98-12$ & $3.26-3.825 .01-5.75$ & 7.05 & - \\
\hline$[30]$ & TAR & $29 \times 20.5$ & $2.98-10.76$ & $3.5,5.5$ & $<6$ & - \\
\hline Proposed work & HRW/CCLL & $73 \times 45$ & $2.6-13.7$ & $4.49-6.64$ & 9.8 & 0.67 \\
\hline
\end{tabular}

SIR: step impedance resonator, SRR: split-ring resonator, CPW: coplanar waveguide, CSRR: complementary split-ring resonator, DGS: defected ground structures, RPR: rectangular parasitic resonator, TAR: triarm resonator.

In order to verify the proposed design mechanism, the resonance characteristics for generating the notch poles were studied, and the conventional Vivaldi antenna loaded with HWR and CCLL was realized and measured. The first notched pole of the antenna is obtained employing a metal stub fed by the antenna, while the second notched pole is obtained by etching a capacitor loop on the radiant patch. Besides, the selectivity of the notch band is discussed. By comparing the simulation results with the measurement results, the two results are consistent. Based on the above results, the proposed new antenna has a proper frequency selection performance of the notch band, good impedance matching, and stable radiation directivity in the passband. With these unique features, the proposed antenna is suitable for UWB applications.

\section{Data Availability}

The data used to support the findings of this study are available from the corresponding author upon request.

\section{Conflicts of Interest}

The authors declare that they have no conflicts of interest.

\section{Acknowledgments}

This work was supported in part by the National Natural Science Foundation of China (Nos. U1637212 and 61605177), the National Defense Pre-Research Foundation of China (61404130402), the Fund for Shanxi'1331 Project' Key Subject Construction, and the Scientific and Technological Innovation Programs of Higher Education Institutions in Shanxi.

\section{References}

[1] Federal Communications Commission, Revision of Part 15 of the Commission's Rules Regarding Ultra-wideband Transmission Systems, First Report and Order FCC 02-48, Federal Communications Commission, Washington, DC, USA, 2002.

[2] T. R. Muthu and A. Thenmozhi, "Metamaterial inspired ultra wide band notched reconfigurable MIMO antenna for cognitive radio platform and wireless applications," Journal of Optoelectronics and Advanced Materials, vol. 20, no. 9-10, pp. 486-492, 2018.
[3] H. A. E. Elobaid, S. K. A. Rahim, M. Himdi, X. Castel, and M. A. Kasgari, "A transparent and flexible polymer-fabric tissue UWB antenna for future wireless networks," IEEE Antennas and Wireless Propagation Letters, vol. 16, pp. 1333-1336, 2017.

[4] W. T. Li, Y. Q. Hei, H. Subbaraman, X. W. Shi, and R. T. Chen, "Novel printed filtenna with dual notches and good out-ofband characteristics for UWB-MIMO applications," IEEE Microwave and Wireless Components Letters, vol. 26, no. 10, pp. 765-767, 2016.

[5] G. Gao, B. Hu, C. Yang, S. Wang, and R. Zhang, "Design of a dual band-notched UWB antenna and improvement of the $5.5 \mathrm{GHz}$ WLAN notched characteristic," Journal of Electromagnetic Waves and Applications, vol. 33, no. 14, pp. 1834$1845,2019$.

[6] A. K. Gautam, L. Kumar, B. K. Kanaujia, and K. Rambabu, "Design of compact F-shaped slot triple-band Antenna for WLAN/WiMAX applications," Ieee Transactions on Antennas and Propagation, vol. 64, no. 3, pp. 1101-1105, 2016.

[7] Q.-X. Chu, C.-X. Mao, and H. Zhu, "A compact notched band UWB slot antenna with sharp selectivity and controllable bandwidth," IEEE Transactions on Antennas and Propagation, vol. 61, no. 8, pp. 3961-3966, 2013.

[8] C.-H. Lee, P.-S. Ho, C.-I. G. Hsu, and H.-H. Chen, "Design of balanced band-notched UWB filtering high-gain slot antenna," Microwave and Optical Technology Letters, vol. 60, no. 3, pp. 615-620, 2018.

[9] N. Ojaroudi, "Compact uwb monopole antenna with enhanced bandwidth using rotated L-shaped slots and parasitic structures," Microwave and Optical Technology Letters, vol. 56, no. 1, pp. 175-178, 2014.

[10] B. Wang, D. Yang, and K. Sun, "Design and analysis of a compact omnidirectional UWB slot antenna," Microwave and Optical Technology Letters, vol. 61, no. 8, pp. 1917-1923, 2019.

[11] L. H. Ye and Q. X. Chu, "Improved band-notched UWB slot antenna," Electronics Letters, vol. 45, no. 25, 2009.

[12] S. S. Abdpour, N. Azadi-Tinat, H. Oraizi, and J. Ghalibafan, "Design of WLAN/WiMAX band notch super-wideband microstrip fractal antennas," International Journal of Microwave and Wireless Technologies, vol. 11, no. 8, pp. 844-850, 2019.

[13] K. A. Alshamaileh, M. J. Almalkawi, and V. K. Devabhaktuni, "Dual band-notched microstrip-fed vivaldi antenna utilizing compact EBG structures," International Journal of Antennas and Propagation, vol. 2015, Article ID 439832, 7 pages, 2015.

[14] J. Marimuthu and M. Esa, "Compact UWB PCML bandpass filter with L- and C-shaped resonator," Electronics Letters, vol. 44, no. 6, pp. 419-421, 2008. 
[15] D. Yadav, M. P. Abegaonkar, S. K. Koul, V. Tiwari, and D. Bhatnagar, "A compact dual band-notched UWB circular monopole antenna with parasitic resonators," AEU-International Journal of Electronics and Communications, vol. 84, pp. 313-320, 2018.

[16] K. Zhang, Y. Li, and Y. Long, "Band-notched UWB printed monopole antenna with a novel segmented circular patch," IEEE Antennas and Wireless Propagation Letters, vol. 9, pp. 1209-1212, 2010.

[17] B. Chen, W. Leng, A. G. Wang, and G. H. Zhao, "Compact ultra-wideband antenna with reconfigurable notched bands," Electronics Letters, vol. 48, no. 19, pp. 1175-U1, 2012.

[18] J. Ghimire and D. Y. Choi, "Design of a compact ultrawideband U-shaped slot etched on a circular patch antenna with notch band characteristics for ultrawideband applications," International Journal of Antennas and Propagation, vol. 2019, Article ID 8090936, 10 pages, 2019.

[19] H. Hosseini, H. R. Hassani, and M. H. Amini, "Miniaturised multiple notched omnidirectional UWB monopole antenna," Electronics Letters, vol. 54, no. 8, pp. 472-474, 2018.

[20] A. T. Wu and B. R. Guan, "A compact CPW-Fed UWB antenna with dual band-notched characteristics," International Journal of Antennas and Propagation, vol. 2013, Article ID 594378, 7 pages, 2013.

[21] C. Z. Zhang, J. Zhang, and L. Li, "Triple band-notched UWB antenna based on SIR-DGS and fork-shaped stubs," Electronics Letters, vol. 50, no. 2, pp. 67-68, 2014.

[22] A. Toktas and M. Yerlikaya, "A compact reconfigurable ultrawideband G-shaped printed antenna with band-notched characteristic," Microwave and Optical Technology Letters, vol. 61, no. 1, pp. 245-250, 2019.

[23] M. Rahman, D. S. Ko, and J. D. Park, "A compact multiple notched ultra-wide band antenna with an analysis of the CSRR-TO-CSRR coupling for portable UWB applications," Sensors, vol. 17, no. 10, 2017.

[24] H.-S. Choi, T.-W. Kim, H.-Y. Hwang, and K. Choi, “An UWB antenna design with adjustable second rejection band using a SIR," IEEE Transactions on Magnetics, vol. 50, no. 2, pp. 913-916, 2014.

[25] M. Ojaroudi and N. Ojaroudi, "Ultra-wideband small rectangular slot antenna with variable band-stop function," IEEE Transactions on Antennas and Propagation, vol. 62, no. 1, pp. 490-494, 2014.

[26] J. Y. Siddiqui, C. Saha, and Y. M. M. Antar, "Compact SRR loaded UWB circular monopole antenna with frequency notch characteristics," IEEE Transactions on Antennas and Propagation, vol. 62, no. 8, pp. 4015-4020, 2014.

[27] W.-A. Li, Z.-H. Tu, Q.-X. Chu, and X.-H. Wu, "Differential stepped-slot UWB antenna with common-mode suppression and dual sharp-selectivity notched bands," IEEE Antennas and Wireless Propagation Letters, vol. 15, pp. 1120-1123, 2016.

[28] M. Rahman, W. T. Khan, and M. Imran, "Penta-notched UWB antenna with sharp frequency edge selectivity using combination of SRR, CSRR, and DGS," AEU-International Journal of Electronics and Communications, vol. 93, pp. 116-122, 2018.

[29] A. K. M. A. H. Siddique, R. Azim, and M. T. Islam, "Compact planar ultra-wideband antenna with dual notched band for WiMAX and WLAN," International Journal of Microwave and Wireless Technologies, vol. 11, no. 7, pp. 711-718, 2019.

[30] R. Azim, M. T. Islam, and A. T. Mobashsher, "Dual bandnotch UWB antenna with single tri-arm resonator," IEEE Antennas and Wireless Propagation Letters, vol. 13, pp. 670$673,2014$. 